九州大学学術情報リポジトリ

Kyushu University Institutional Repository

\title{
Antibacterial activity of moso bamboo shoot skin (Phyllostachys pubescens) against Staphylococcus aureus
}

Tanaka, Akinobu

Department of Agro-environmental Sciences, Faculty of Agriculture, Kyushu University

Kim, Hyo Jung

Department of Agro-environmental Sciences, Faculty of Agriculture, Kyushu University

Oda, Shojiro

Life Design Co. Ltd.

Shimizu, Kuniyoshi

Department of Agro-environmental Sciences, Faculty of Agriculture, Kyushu University

他

http://hdl. handle. net/2324/25647

出版情報: Journal of Wood Science. 57 (6), pp.542-544, 2011-12-01. Springer Japan バージョン :

権利関係: (C) The Japan Wood Research Society 2011 


\section{Title}

Antibacterial activity of moso bamboo shoot skin (Phyllostachys pubescens) against Staphylococcus aureus.

\section{Type of article}

Note

\section{Authors}

Akinobu Tanaka ${ }^{1}$, Hyo Jung $\mathrm{Kim}^{1}$, Shojiro Oda ${ }^{2}$, Kuniyoshi Shimizu ${ }^{1}$, Ryuichiro Kondo ${ }^{1}$

\section{Affiliation}

1. Department of Agro-environmental Sciences, Faculty of Agriculture, Kyushu University, 6-10-1 Hakozaki, Higashi-ku, Fukuoka, 812-8581, Japan

2. Life Design Co. Ltd., 1608 Katsuyamakuroda, Miyako, Fukuoka, 824-0822, Japan

To whom correspondence should be addressed.

Kuniyoshi Shimizu

Address: 6-10-1 Hakozaki, Higashi-ku, Fukuoka, Japan, 812-8581

E-mail: shimizu@agr.kyushu-u.ac.jp

Phone/Fax: +81-92-642-3002

\section{Keywords}

antibacterial activity; moso bamboo shoot skin; Phyllostachys pubescens; Staphylococcus aureus 


\begin{abstract}
This study examined the antibacterial activity of moso bamboo shoot skin (Phyllostachys pubescens). Bamboo shoot skin itself and its dichloromethane extract had antibacterial activity against Staphylococcus aureus. Results suggest the possibility of effective utilization for antibacterial materials of bamboo shoot skins which are mainly scrapped today.
\end{abstract}




\section{Introduction}

Recently, chemical food additives like paraben ${ }^{1-2)}$ have been reported to have harmful effects. However, harmful compounds like paraben are still used as preservatives in foods, cosmetics, or medical products. Meanwhile, the consumer demand for the safety of the additive agents is increasing every year. It has led to be popular movements to reduce the addition of synthetic chemical compounds in foods and cosmetics. Hence, the emergence of materials having less harmful effects, and preferably natural products, would be highly desirable if their safety could be guaranteed. Staphylococcus aureus is a major food pathogen. These bacteria live on human skin and infect the body through wounds or foods. They produce several toxins such as enterotoxin-A and $-\mathrm{D}^{3)}$. These toxins cause abdominal pain, vomiting and diarrhea. Mainly, they grow in foods ; therefore, it is important to prevent their growth in foods. Research into natural products that can achieve this objective has been underway in many laboratories.

Bamboo is well known for its usefulness. For example, its roots and leaves have been used as medicinal products. Also, studies on the medicinal properties of the leaves of bamboo trees have shown the antioxidant, anticancer and antibiotic properties. ${ }^{4-5)}$ From these studies, various active compounds have been separated from the leaves, such as flavones, glycosides, phenolic acids, coumarin lactones, anthraquinones and amino acids. $^{6-10)}$ Also, 2,6-dimethoxy- $p$-benzoquinone obtained from the skin of the bamboo trees and the chitin-binding peptides: Pp-AMP1 and Pp-AMP2 separated from bamboo shoots have antibiotic activities. ${ }^{11-12)}$ Tricin and taxifolin from the bamboo sheath reportedly have antioxidant activity. ${ }^{13)}$ However, studies on the antibacterial activity of the bamboo shoot skin have not been reported.

This study focused on moso bamboo shoot skins (Phyllostachys pubescens), which have been traditionally used for packaging food. For example, bamboo shoot skin is used as a preservative container to maintain the taste of the tea in China and has been used as packaging materials for rice balls and meat in Japan. Fukuoka prefecture is the major production area of bamboo shoots in Japan. A lot of food goods are produced from bamboo shoots annually. At the present time, a large amount of bamboo shoot skin is produced from these industrial food processes. These bamboo shoot skins are often composted. However, it is difficult to use bamboo shoot skins as compost because of their persistence. Hence, most bamboo shoot skins are burned. It is essential to utilize bamboo shoot skins efficiently.

This study aims to examine the antibacterial activity of the moso bamboo shoot skin. 


\section{Materials and methods}

Materials. Moso bamboo shoot skins were used in this study. These were harvested at Miyako town, Fukuoka prefecture, Japan and provided by Life Design Co. Ltd (Fukuoka, Japan). It was dried at room temperature and used for following experiments.

Strains. The test strain was Staphylococcus aureus (NBRC 12732).

Antibacterial assay I. In this experiment, we evaluated the antibacterial activity of moso bamboo shoot skin $(10 \mathrm{~mm} \times 10 \mathrm{~mm}$ plate $)$ itself.

Moso bamboo shoot skins were cut into $10 \mathrm{~mm} \times 10 \mathrm{~mm}$ pieces. Then, these pieces were washed by $70 \%$ ethanol to kill bacteria. These bamboo shoot skins were defined as "untreated bamboo shoot skins". On the other hand, bamboo shoot skin (10 g, $10 \mathrm{~mm} \times$ $10 \mathrm{~mm}$ plates) was sequentially treated by soaking in $n$-hexane $(100 \mathrm{~mL})$, dichloromethane $(100 \mathrm{~mL})$, methanol $(100 \mathrm{~mL})$ and water $(100 \mathrm{~mL})$ for 24 hours, 180 rpm to prepare "the extract-free bamboo shoot skins" which were defined as "treated bamboo shoot skins". A single colony of the test strain was taken and added to $20 \mathrm{~mL}$ of nutrient broth (NB) medium. This medium was incubated at $37^{\circ} \mathrm{C} \pm 1^{\circ} \mathrm{C}, 160 \mathrm{rpm}$ for 12 hours. After that, NB medium was added to the bacterial suspension to prepare a bacterial concentration at $10^{5} \mathrm{CFU} / \mathrm{mL}$. Five $\mathrm{mL}$ of $\mathrm{NB}$ medium, $50 \mu \mathrm{L}$ of bacteria suspension and a piece of bamboo shoot skin were incubated at $37^{\circ} \mathrm{C}, 200 \mathrm{rpm}$ for 9 hours. Then, the bamboo shoot skin was removed from the medium. Finally, bacteria growth was measured by a micro plate reader $(630 \mathrm{~nm})$. The statistical difference between each group was determined by Tukey's test. Scheme of this assay is shown in Fig .1

Antibacterial assay II. In this experiment, we evaluated the antibacterial activity of extracts from moso bamboo shoot skin.

Moso bamboo shoot skins (powder, $100 \mathrm{~g}$ ) were serially extracted with $n$-hexane (1L, weight of $n$-hexane extract was $0.17 \mathrm{~g}$ ), dichloromethane $(1 \mathrm{~L}, 0.18 \mathrm{~g}$ ), methanol (1L, $0.93 \mathrm{~g}$ ) and water (1L, $2.41 \mathrm{~g})$ for 24 hours, $180 \mathrm{rpm}$. A single colony of test strain was taken and added to $20 \mathrm{~mL}$ of $\mathrm{NB}$ medium. This medium was incubated at $37^{\circ} \mathrm{C} \pm 1{ }^{\circ} \mathrm{C}$, $160 \mathrm{rpm}$ for 12 hours. After that, NB medium was added to the bacterial suspension to prepare a bacterial concentration at $10^{5} \mathrm{CFU} / \mathrm{mL}$. Each extract (n-hexane, dichloromethane, methanol and water) was dissolved in dimethyl sulfoxide (DMSO) at maximum concentration. Subsequently, serial 2-fold dilutions of the test extracts were prepared in DMSO. Into each well of a 96 well plate, $89 \mu \mathrm{L}$ of NB medium, $10 \mu \mathrm{L}$ of bacteria suspension and $1 \mu \mathrm{L}$ of DMSO with or without each extract were added. The plate was incubated at $37^{\circ} \mathrm{C} \pm 1{ }^{\circ} \mathrm{C}, 1160 \mathrm{rpm}$ for 12 hours. The MIC (minimum inhibitory concentration) was the lowest concentration of the test extract that 
demonstrated no visible growth.

\section{Results and discussion}

The results of antibacterial assay I were shown in Fig. 2. The absorbance at $630 \mathrm{~nm}$ of each sample (control, untreated and treated) were $0.294 \pm 0.0150,0.169 \pm 0.0075$ and $0.233 \pm 0.0229$, respectively. Absorbances of untreated and treated samples were significantly lower than that of control. From this result, it was determined that bamboo shoot skin itself can inhibit the growth of S. aureus. Also, the absorbance of the untreated sample $(0.169 \pm 0.0075)$ was lower than that of treated sample $(0.233 \pm$ 0.0229). This result indicates that untreated bamboo shoot skin had stronger activity than the treated one. The difference in activities between the untreated and treated bamboo shoot skins indicates that bamboo shoot skin includes some antibacterial compounds that can be extracted by solvents. It seems that antibacterial compounds were eluted from bamboo shoot skin itself into medium and expressed antibacterial activity against $S$. aureus. Next, we evaluated the antibacterial activities of extracts prepared from the bamboo shoot skin.

The results of antibacterial assay II were shown in Table 1. The MIC of dichloromethane extract was $200 \mu \mathrm{g} / \mathrm{mL}$. Also, MICs ( $n$-Hexane, methanol, and water extracts) couldn't be decided in this condition. Only the dichloromethane extract showed strong antibacterial activity.

From these experiments, two important facts were elucidated. First, bamboo shoot skin has antibacterial activity against $S$. aureus. Second, the active compounds can be extracted by dichloromethane. Previously 2,6-dimethoxy- $p$-benzoquinone have been reported to be isolated from the skin of the bamboo trees as an antibacterial compound. ${ }^{11)}$ However, 2,6-dimethoxy- $p$-benzoquinone have not been detected in the extracts of bamboo shoot skin by HPLC analysis (date not shown). These results indicated that other antibacterial compound other than 2,6-dimethoxy- $p$-benzoquinone have been existed in the bamboo shoot skin. Currently, bamboo shoot skins discarded from food processing are mainly incinerated while the rest is composted. This study indicated the possibility of bamboo shoot skins as antibacterial materials. The consumer demand for food safety and safe additives are increasing every year; bamboo shoot skins might fill these demands as packaging materials to keep food safety. Also, the problem with using bamboo shoot skins as compost is their environmental persistence. One of the reasons for this persistence is their antibacterial activity. However, antibacterial activity can be reduced by sequential extraction. Therefore, it can be assumed that treated bamboo shoot skins would be more easily decomposed and 
converted to compost.

This is the first report about the antibacterial activity of bamboo shoot skins. Until now, the use known for bamboo shoot skins were mainly for compost. However, this study showed the possibility of bamboo shoot skins as antibacterial materials. This study may make it possible to utilize bamboo shoot skins more effectively. 


\section{References}

1) Ishiwatari S, Suzuki T, Hitomi T, Yoshino T, Matsukuma S, Tsuji T (2007) Effects of methyl paraben on skin keratinocytes. Journal of Applied Toxicology 27:1-9

2) Handa O, Kokura S, Adachi S, Takagi T, Naito Y, Tanigawa T, Yoshida N, Yoshikawa

$\mathrm{T}$ (2006) Methylparaben potentiates UV-induced damage of skin keratinocytes. Toxicology 227:62-72

3) Jacquelyn G. Black (2007), Microbiology, Maruzen Co. Ltd., Tokyo, pp.686 - 687

4) Lee H.-O, Baek S.-H, Han D.-M (2001) Antimicrobial effects of Chamaecyparis obtusa essential oil. Korean Journal of Applied Microbiology and Biotechnology 29:253-257

5) Zhang Y, Jiao J, Liu C, Wu X, Zhang Y (2008) Isolation and purification of four flavone C-glycosides from antioxidant of bamboo leaves by macroporous resin column chromatography and preparative high-performance liquid chromatography. Food Chemistry 107:1326-1336

6) Lu B.-Y, Zhang Y, Wu X.-Q (2005) Advances in studies on antioxidative activity and cardio-cerebrovascular pharmacology of bamboo-leaf-flavonoids. Linchan Huaxue Yu Gongye/Chemistry and Industry of Forest Products 25:120-124

7) Jiao J, Zhang Y, Liu C, Liu J, Wu X, Zhang Y (2007) Separation and purification of tricin from an antioxidant product derived from bamboo leaves. Journal of Agricultural and Food Chemistry 55:10086-10092

8) Hasegawa T, Tanaka A, Hosoda A, Takano F, Ohta T (2008) Antioxidant C-glycosyl flavones from the leaves of Sasa kurilensis var. gigantean. Phytochemistry 69: 1419-1424

9) Zhang Y, Yao X, Bao B, Zhang Y (2006) Anti-fatigue activity of a triterpenoid-rich extract from chinese bamboo shavings (Caulis bamfusae in taeniam). Phytotherapy Research 20:872-876

10) Kurokawa T, Itagaki S, Yamaji T, Nakata C, Noda T, Hirano T, Iseki K (2006) Antioxidant activity of a novel extract from bamboo grass (AHSS) against ischemia-reperfusion injury in rat small intestine. Biological and Pharmaceutical Bulletin 29:2301-2303

11) Nishina A, Hasegawa K.-I, Uchibori T, Seino H, Osawa T (1991) 2,6-dimethoxy-p-benzoquinone as an antibacterial substance in the bark of Phyllostachys heterocycla var. Pubescens, a species of thick-stemmed bamboo. Journal of Agricultural and Food Chemistry 39:266-269

12) Fujimura M, Ideguchi M, Minami Y, Watanabe K, Tadera K (2005) Amino acid sequence and antimicrobial activity of chitin-binding peptides, Pp-AMP 1 and Pp-AMP 
2, from Japanese bamboo shoots (Phyllostachys pubescens). Bioscience, Biotechnology and Biochemistry 69:642-645

13) Katsuzaki H, Sakai K, Achiwa Y, Imai K, Komiya $T$ (1999) Isolation of antioxidative compounds from bamboo shoots sheath. Nippon Shokuhin Kagaku Kogaku Kaishi 46:491-493 


\section{Figure legends}

Fig. 1 Scheme of antibacterial assay I : antibacterial activity of bamboo shoot skin

Fig. 2 Antibacterial activity of bamboo shoot skin against $S$. aureus

Each value is expressed as the mean \pm S.D $(n=3)$. abc : different letters show significant difference at $P<0.01$ by Turkey's test. A significant difference is apparent between the Control and untreated, Treated bamboo shoot skin in antibacterial activity. Untreated : untreated bamboo shoot skin. Treated : Treated bamboo shoot skin. 


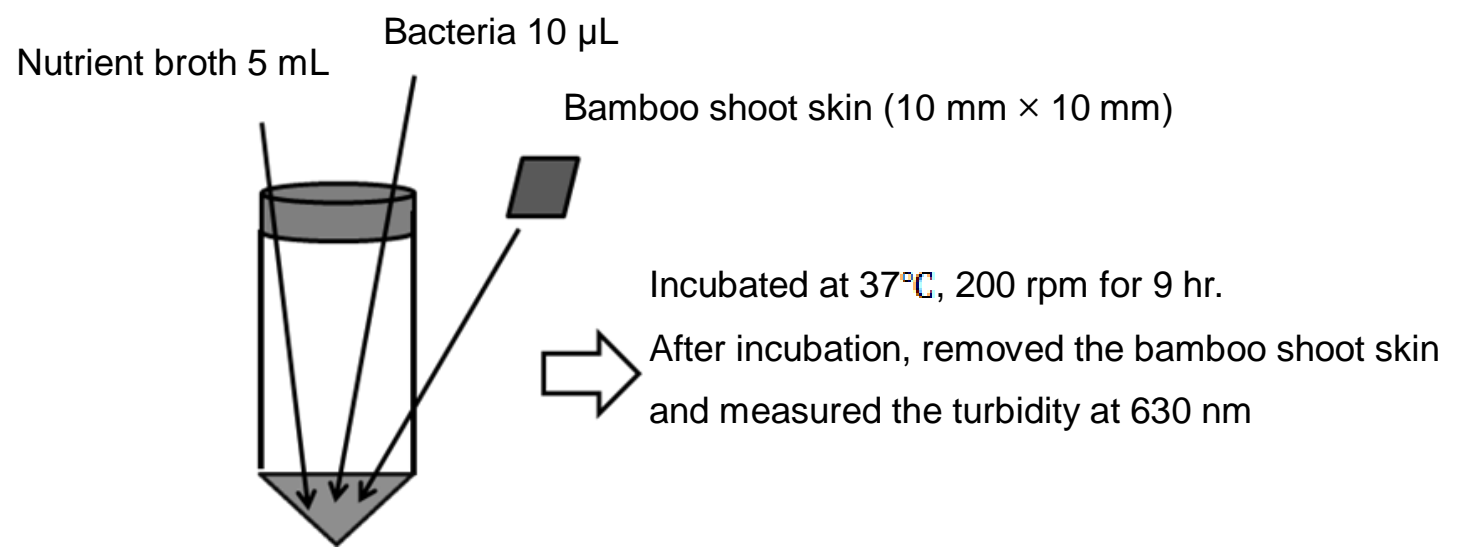

Fig. 1 Scheme of antibacterial assay I : antibacterial activity of bamboo shoot skin 


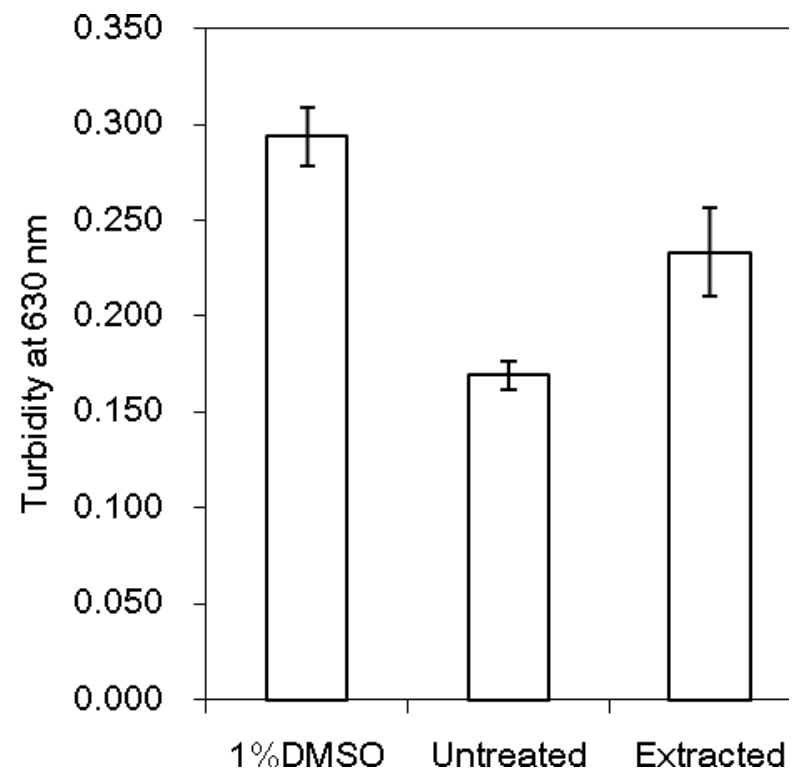

Fig. 2 Antibacterial activity of bamboo shoot skin against S.aureus 